\title{
DIVERSIDADE FLORÍSTICA E ESTRUTURA FITOSSOCIOLÓGICA DE UM GRADIENTE TOPOGRÁFICO EM FLORESTA ESTACIONAL SEMIDECIDUAL SUBMONTANA, MG
}

\author{
Priscila Bezerra de Souza ${ }^{1 *}$, João Augusto Alves Meira Neto², Agostinho Lopes de Souza ${ }^{2}$
}

*Autora para correspondência: pri_ufv@yahoo.com.br

RESUMO: Neste trabalho, objetivou-se determinar a diversidade florística e a estrutura fitossociológica da vegetação arbórea em gradiente topográfico de Floresta Estacional Semidecidual Submontana (Mata do Mumbaça), município de Dionísio-MG $\left(19^{\circ} 48^{\prime} \mathrm{S}\right.$ e $\left.42^{\circ} 31^{\prime} \mathrm{W}\right)$. Todos os indivíduos lenhosos com diâmetro ao nível do peito $(1,3 \mathrm{~m}) \geq 10 \mathrm{~cm}$ foram medidos em 1,2 ha distribuídos em 120 parcelas $10 \times 10 \mathrm{~m}$ de modo a contemplar quatro unidades topográficas (Rampa Baixa, Baixa Encosta, Alta Encosta e Topo). Foram amostrados 2990 indivíduos com um total de 132 espécies, pertencentes a 92 gêneros, representados em 38 famílias. As faixas Alta Encosta e Topo apresentaram maior número de indivíduos, 870 e 822, respectivamente. As faixas que apresentaram maiores valores de área basal foram Rampa Baixa 24,60 m²/ha $\mathrm{m}^{-1} \mathrm{e}$ Topo $19,36 \mathrm{~m}^{2} / \mathrm{ha}^{-1}$. Somente Casearia arborea e Anadenanthera peregrina estiveram presentes entre as dez espécies mais importantes nas quatro faixas, porém algumas espécies ocuparam posições de destaque nas diferentes áreas estudadas como Anadenanthera peregrina e Xylopia aromatica no Topo, Myrcia fallax e Dalbergia nigra na Alta Encosta, Tapirira guianensis e Hortia arborea na Baixa Encosta e Apuleia leiocarpa e Siparuna guianensis na Rampa Baixa.

Palavras-chave: Fitossociologia, zona de amortecimento, Parque Estadual do Rio Doce.

\section{DIVERSITY AND PHYTOSOCIOLOGICAL STRUCTURE OF A TOPOGRAPHIC GRADIENT IN SEASONAL SEMIDECIDUAL FOREST OF MATA MUMBAÇA, MG}

\begin{abstract}
This study aimed to determine the floristic diversity and phytossociological structure of trees in a topographic gradient of lower montane semideciduous forest (Mata do mumbaça), municipality of Dionisio-MG (19 ${ }^{\circ} 48^{\prime} \mathrm{S}$ and $\left.42^{\circ} 31^{\prime} \mathrm{W}\right)$. All woody individuals with diameter at breast height $(1.3 \mathrm{~m}) \geq 10 \mathrm{~cm}$ were measured on 1.2 ha distributed in 120 plots $10 \times 10 \mathrm{~m}$ in order to include four topographic units (Low Ramp, Lower Slope Upper Slope and top). It was sampled 2990 individuals with a total of 132 species belonging to 92 genera, represented in 38 families. The Upper Slope and the Top showed higher numbers of individuals, 870 and 822, respectively. The tracks with higher levels of basal area were Lower Slope 24, $60 \mathrm{~m}^{2} / \mathrm{ha}^{-1}$ and Top 19, $36 \mathrm{~m}^{2} / \mathrm{ha} \mathrm{a}^{-1}$. Only Casearia arborea and Anadenanthera peregrina were present among the ten most important species in the four tracks, but some species occupie prominent positions in the different areas studied as A. peregrina and Xylopia aromatica on Top, Myrcia fallax and Dalbergia nigra in the Upper Slope, Tapirira guianensis and Hortia arborea in Lower Slope and Apuleia leiocarpa and Siparuna guianensis in Low Ramp.
\end{abstract}

Key words: Phytosociology, buffer zone, Parque Estadual do Rio Doce.

\section{INTRODUÇÃO}

Nas últimas décadas, houve considerável avanço nos estudos de comunidades florestais, principalmente por causa de sua importância para a conservação da diversidade biológica. Essa importância se torna cada dia mais acentuada, em razão do processo desordenado de ocupação do solo que, nas mais diversas regiões do país, tem transformado formações florestais contínuas em fragmentos. Além disso, geralmente os remanescentes estão localizados em propriedades particulares e estão sujeitos às mais diversas perturbações (OLIVEIRA FILHO et al., 1994).

Vários estudos têm apontado que um dos principais fatores atuando na composição florística e estrutura das florestas é a heterogeneidade ambiental, cujos efeitos podem ser observados mesmo no interior de pequenos fragmentos (BOTREL et al., 2002; CARVALHO et al., 2005; OLIVEIRA FILHO et al., 1994; ROCHA et al., 2005). Essa heterogeneidade é resultado da diversidade de fatores que interagem nas comunidades e a resposta das espécies a esses fatores faz com que cada local tenha características próprias e características que são comuns a outros locais, possibilitando observar tendências. Essas tendências podem responder a algumas perguntas e gerar várias outras, funcionando com força motriz para novos estudos (RODRIGUES et al., 2007).

Numa escala local, a topografia tem sido considerada como a mais importante variável na distribuição espacial e

${ }^{1}$ Universidade Federal do Tocantins - Gurupi, Tocantins, Brasil

${ }^{2}$ Universidade Federal de Viçosa - Viçosa, Minas Gerais, Brasil

Cerne, Lavras, v. 19, n. 3, p. 489-499, jul./set. 2013 
na estrutura das florestas tropicais, porque ela comumente corresponde a mudanças nas propriedades do solo, particularmente no regime de água e na fertilidade (CARVALHO et al., 2005; ESPÍRITO SANTO et al., 2002; FERREIRA JÚNIOR et al., 2007).

Em fragmentos de Floresta Estacional Semidecidual localizados em regiões de relevo acidentado, alterações na distribuição da vegetação arbórea ao longo de gradientes topográficos e suas relações com fatores edáficos necessitam ser analisadas visando à definição de estratégias para conservação e manejo desses remanescentes bem como a restauração florestal em áreas já degradadas (MARTINS et al., 2003).

O conhecimento da organização estrutural das populações de espécies arbustivo-arbóreas, por meio de estudos fitossociológicos, é base para a definição de estratégias de manejo e conservação de remanescentes florestais e restauração florestal em áreas degradadas. Informações sobre o número de indivíduos por espécie, espécies dominantes e espécies raras devem ser consideradas nos projetos de restauração florestal, visando à sustentabilidade dos ecossistemas a serem restaurados (PINTO et al., 2007).

O presente estudo visa a testar a hipótese de que a distribuição de espécies arbóreas num fragmento de Floresta Estacional Semidecidual Submontana, no Vale do Rio Doce-MG oscila ao longo de um gradiente geomorfológico. Com isso o objetivo deste trabalho foi determinar a diversidade e a estrutura fitossociológica da vegetação arbórea de um gradiente topográfico, visando a subsidiar ações de manejo e recuperação de áreas com características similares.

\section{MATERIAL E MÉTODOS}

O estudo foi realizado em um fragmento de Floresta Estacional Semidecidual Submontana, denominado como Mata do Mumbaça, propriedade da Arcellor Mittal Florestas Ltda., município de Dionísio-MG (19²48'S e $\left.42^{\circ} 31^{\prime} \mathrm{W}\right)$. A Mata do Mumbaça está localizada ao sul do Parque Estadual do Rio Doce (PERD) e compreende um contínuo florestal na Zona de Amortecimento do PERD, com aproximadamente 1.500 ha, cuja vegetação atual encontra-se em regeneração natural há 25 anos, após corte raso, sendo originalmente classificada como mata média alta com bambuzóides e graminóides (GILHUIS, 1986).

O clima da região é do tipo Aw (clima tropical úmido), com um período de chuva e outro de estiagem bem definido (GILHUIS, 1986). A precipitação média anual é de $1.450 \mathrm{~mm}$ e a temperatura média anual está entre 20 e $23^{\circ} \mathrm{C}$. Os solos são do tipo Latossolo Vermelho-Amarelo e, de maneira geral, são ácidos e de baixa fertilidade natural, característica comum aos solos da região do Vale do Rio Doce-MG. O relevo é ondulado a fortemente ondulado e possui uma textura variando de argilosa a muito argilosa (LOMBARDI; GONÇALVES, 2000).

Para a amostragem foi utilizado o método de parcelas (MUELLER-DOMBOIS; ELLENBERG, 1974). Foram demarcadas, na área de estudo, 120 parcelas contíguas de $10 \times 10 \mathrm{~m}$, correspondendo a uma área amostral total de $12.000 \mathrm{~m}^{2}$, distribuídas de modo a contemplar o gradiente topográfico, diante do contexto, dividiu-se o gradiente em quatro faixas (Rampa Baixa, Baixa Encosta, Alta Encosta e Topo), onde, cada uma das faixas foram compostas de 30 parcelas contíguas ao longo da inclinação do terreno. Dessa forma, as parcelas de 1 a 30 foram instaladas na faixa Rampa Baixa, parcelas de 31 a 60 na faixa Baixa Encosta, parcelas de 61 a 90 na faixa Alta Encosta e parcelas de 91 a 120 na faixa Topo. Foram amostrados todos os indivíduos com circunferência a $1,30 \mathrm{~m}$ do solo (CAP) maior ou igual a $10 \mathrm{~cm}$.

Para a compreensão da estrutura horizontal da comunidade, foram utilizados os parâmetros fitossociológicos de densidade, dominância e frequência, bem como o valor de importância (VI) e cobertura (VC), que foram obtidos pelo programa Mata Nativa 2 (CONSULTORIA E DESENVOLVIMENTO DE SISTEMAS - CIENTEC, 2006), segundo as interpretações de Mueller-Dombois e Ellemberg (1974) e Pielou (1975). $\mathrm{O}$ índice de diversidade de Shannon-Wiener ( $\left.\mathrm{H}^{\prime}\right)$ e a equabilidade (J') foram calculados de acordo com Pielou (1975).

Para as análises de similaridade e diversidade entre as faixas topográficas amostradas montou-se uma matriz de presença e ausência com as espécies e as diferentes faixas, aplicando-se o índice de similaridade de Sørensen (Ss), Brower e Zar (1984). Para interpretar a similaridade florística entre as faixas topográficas, utilizou-se o método de médias não ponderadas (UPGMA - Unweighted Pair Group Method Using Arithmetic Averages), e para a visualização das ligações florísticas utilizou-se o programa MVSP (versão 3.1) (KOVACH, 1999). A identificação taxonômica foi realizada, por meio de comparações com material do Herbário VIC da Universidade Federal de Viçosa, literatura especializada e consultas a especialistas, quando necessário. Para atualização dos binômios específicos foi utilizado o site do Missouri Botanical

Cerne, Lavras, v. 19, n. 3, p. 489-499, jul./set. 2013 
Garden, disponível em MOBOT (2012), no ano de 2012. O sistema de classificação taxonômica adotado foi APG III (ANGIOSPERM PHYLOGENY GROUP - APG, 2009).

\section{RESULTADOS E DISCUSSÃO}

Foi amostrado, nas quatro faixas topográficas (Rampa Baixa, Baixa Encosta, Alta Encosta e Topo) um total de 2990 indivíduos arbóreos, pertencentes a 38 famílias, 92 gêneros e 132 espécies (Tabela 1). Os dados de riqueza mostraram uma riqueza compatível a outros estudos realizados em Florestas Estacionais Semideciduais de Minas Gerais (DRUMOND; MEIRA-NETO, 1999; LOPES et al., 2002; RIBAS et al., 2003; SILVA et al., 2003).

Tabela 1 - Lista Florística de 1,20 hectare de uma Floresta Estacional Semidecidual Submontana, município de Dionísio MG.

Table 1 - Floristic List of 1.20 hectare of Semideciduous Submontane forest, municipality of Dionysus - MG.

\begin{tabular}{|c|c|}
\hline $\begin{array}{l}\text { Famílias / } \\
\text { Subfamílias }\end{array}$ & Espécies \\
\hline \multirow{4}{*}{ Anacardiaceae } & $\begin{array}{l}\text { Astronium fraxinifolium Schott ex } \\
\text { Spreng. }\end{array}$ \\
\hline & Spondias lutea $\mathrm{L}$. \\
\hline & Tapirira guianensis Aubl. \\
\hline & Tapirira obtusa (Benth.) D.J. Mitch. \\
\hline \multirow{9}{*}{ Annonaceae } & Anona cacans Warm. \\
\hline & Duguetia lanceolata St. Hil. \\
\hline & Guatteria gomeziana Saint-Hilaire \\
\hline & Guatteria villosissima St.Hilaire \\
\hline & Rollinia dolichopetala R.E. Fr. \\
\hline & Rollinia sylvatica (A. St.-Hil.) Martius \\
\hline & Unonopsis lindmanii R.E. Fr. \\
\hline & Xylopia aromatica (Lam.) Mart. \\
\hline & Xylopia sericea A. St.-Hil. \\
\hline \multirow[b]{2}{*}{ Apocynaceae } & Aspidosperma parvifolium A. DC. \\
\hline & Himatanthus phagedaenicus (Mart.) \\
\hline \multirow[t]{2}{*}{ Asteraceae } & $\begin{array}{l}\text { Austrocritonia velutina (Gardner) R.M. } \\
\text { King \& H. Rob. }\end{array}$ \\
\hline & Piptocarpha macropoda (DC.) Baker \\
\hline
\end{tabular}

To be continued...
Tabela 1 - Continuação...

Table 1 - Continued..

\begin{tabular}{|c|c|}
\hline $\begin{array}{l}\text { Famílias / } \\
\text { Subfamílias }\end{array}$ & Espécies \\
\hline \multirow[t]{2}{*}{ Asteraceae } & $\begin{array}{l}\text { Vernonanthura divaricata (Spreng.) } \\
\text { H.Rob. }\end{array}$ \\
\hline & Vernonia sp.1 \\
\hline \multirow{6}{*}{ Bignoniaceae } & Adenocalyma subsessilifolium DC. \\
\hline & $\begin{array}{l}\text { Cybistax antisyphilitica (Mart.) Mart. ex } \\
\text { A. DC. }\end{array}$ \\
\hline & $\begin{array}{l}\text { Handroanthus riodocensis (A.H. Gentry) } \\
\text { S. O. Grose }\end{array}$ \\
\hline & Jacaranda macrantha Cham. \\
\hline & $\begin{array}{l}\text { Sparattosperma leucanthum (Vell.) K. } \\
\text { Schum. }\end{array}$ \\
\hline & $\begin{array}{l}\text { Tabebuia chrysotricha (Mart. ex DC.) } \\
\text { Standl. }\end{array}$ \\
\hline Bixaceae & Bixa arborea Huber \\
\hline Boraginaceae & Cordia sellowiana Cham. \\
\hline \multirow{2}{*}{ Celastraceae } & Maytenus communis Reissek \\
\hline & Maytenus robusta Reissek \\
\hline \multirow{8}{*}{ Chrysobalanaceae } & Couepia monteclarensis Prance. \\
\hline & Couepia schottii Fritsch \\
\hline & Hirtella bicornis Mart. ex Zucc \\
\hline & Hirtella hebeclada Moric. ex A.DC. \\
\hline & $\begin{array}{l}\text { Hirtella racemosa Lam. var. hexandra } \\
\text { (Willd. ex Roem. \& Schult.) }\end{array}$ \\
\hline & Licania kunthiana Hook. f. \\
\hline & $\begin{array}{l}\text { Licania octandra (Hoffmanns. ex Roem. } \\
\text { \& Schult.) }\end{array}$ \\
\hline & Parinari brasiliensis (Schott) Hook \\
\hline Clusiaceae & Vismia martiana Reichardt \\
\hline Elaeocarpaceae & Sloanea guianensis (Aubl.) Benth. \\
\hline Erythroxylaceae & Erythroxylum pelleterianum A. St.-Hil. \\
\hline \multirow{4}{*}{ Euphorbiaceae } & Alchornea glandulosa Poepp. \& Endl. \\
\hline & Mabea fistulifera Mart. \\
\hline & Pera glabrata (Schott) Poepp. ex Baill. \\
\hline & Pera heteranthera (Schrank) I.M.Johnst. \\
\hline \multirow{2}{*}{$\begin{array}{l}\text { Fabaceae } \\
\text { Caesalpinioideae }\end{array}$} & Apuleia leiocarpa (Vogel) J.F. Macbr \\
\hline & $\begin{array}{l}\text { Cassia ferruginea (Schrader) Schrader } \\
\text { ex DC. }\end{array}$ \\
\hline
\end{tabular}

Continua.. To be continued...

Cerne, Lavras, v. 19, n. 3, p. 489-499, jul./set. 2013 
Tabela 1 - Continuação...

Table 1 - Continued...

\begin{tabular}{ll}
\hline Famílias / & Espécies \\
Subfamílias &
\end{tabular}

\begin{tabular}{|c|c|}
\hline \multirow{4}{*}{$\begin{array}{l}\text { Fabaceae } \\
\text { Caesalpinioideae }\end{array}$} & Cassia multijuga Rich. \\
\hline & Copaifera lagsdorffii Desf. \\
\hline & $\begin{array}{l}\text { Senna macrantera (DC. ex Collad.) H.S. } \\
\text { Irwin \& Barneby }\end{array}$ \\
\hline & Tachigali subvelutina (Benth.) ined. \\
\hline \multirow{7}{*}{$\begin{array}{l}\text { Fabaceae } \\
\text { Mimosoideae }\end{array}$} & $\begin{array}{l}\text { Abarema brachystachya (DC) Barneby } \\
\text { \& Grimes }\end{array}$ \\
\hline & Acacia polyphylla DC. \\
\hline & Inga capitata Desv. \\
\hline & Inga leptantha Benth. \\
\hline & Inga sp.1 \\
\hline & $\begin{array}{l}\text { Pseudopiptadenia contorta (DC.) } \\
\text { G.P.Lewis \& M.P.Lima }\end{array}$ \\
\hline & $\begin{array}{l}\text { Stryphnodendron guianense (Aubl.) } \\
\text { Benth. }\end{array}$ \\
\hline \multirow{9}{*}{$\begin{array}{l}\text { Fabaceae } \\
\text { Papilionoideae }\end{array}$} & Dalbergia brasiliensis Vogel \\
\hline & Dalbergia foliolosa Benth. \\
\hline & Dalbergia nigra (Vell.) Allemao ex Benth. \\
\hline & Deguelia costata (Benth.) Az.-Tozzi \\
\hline & Hymenolobium janeirense Kuhlm. \\
\hline & Machaerium brasiliense Vogel \\
\hline & Plathypodium elegans Vogel \\
\hline & Swartzia apetala Radii \\
\hline & Swartzia polyphylla DC. \\
\hline Humiriaceae & $\begin{array}{l}\text { Sacoglottis mattogrossensis Malme var. } \\
\text { mattogrossensis }\end{array}$ \\
\hline Icacinaceae & Emmotun acuminatum (Benth.) Miers \\
\hline Lacistemataceae & Lacistema pubescens Mart. \\
\hline \multirow{7}{*}{ Lauraceae } & Aniba firmula (Ness \& C. Mart.) Mez \\
\hline & Cryptocarya aschersoniana $\mathrm{Mez}$ \\
\hline & Nectandra oppositifolia Nees \& Mart. \\
\hline & Nectandra reticulata (Ruiz \& Pav.) Mez \\
\hline & Ocotea corymbosa (Meisn.) Mez \\
\hline & Ocotea diospyrifolia (Meisn.) Mez \\
\hline & Ocotea dispersa (Nees) Mez \\
\hline
\end{tabular}

Continua...

To be continued...
Tabela 1 - Continuação...

Table 1 - Continued..

Famílias / Espécies
Subfamílias

Ocotea odorifera (Vellozo) Rohwer

Ocotea villosa Kosterm.

Lauraceae Phyllostemonodaphne geminiflora (Mez) Kosterm.

Urbanodendron verrucosum (Nees) Mez

\begin{tabular}{ll} 
& Urbanodendron verrucosum (Nees) Mez \\
\hline Lecythidaceae & Lecythis lurida (Miers) S.A. Mori \\
\hline \multirow{2}{*}{ Malpighiaceae } & Byrsonima crispa A. Juss. \\
& Byrsonima sericea A.DC. \\
\hline
\end{tabular}

Malvaceae Pseudobombax grandiflorum (Cav.) A. Robyns

Miconia albicans Triana

Miconia calvescens Schrank \& Mart. ex DC.

Melastomataceae

Miconia cinnamoniifolia (Jacq.) Triana

Miconia sellowiana Naudin

Miconia urophylla DC.

Guarea macrophylla Vahl

Meliaceae Guarea pendula Ramalho Pinheiro \& Penn.

\begin{tabular}{ll}
\hline & Brosimum glaziovii Taub. \\
Moraceae & Helicostylis tomentosa (Poepp. \& Endl.) \\
& Rusby \\
& Sorocea bonplandii (Baill.) W.C. Burger, \\
& Lanj. \& Wess. Boer \\
\hline Myrsinaceae & Myrsine umbellata Mart. \\
\hline & Campomanesia laurifolia Gardner \\
& Campomanesia sp.1 \\
& Eugenia sp.1 \\
& Gomidesia cordiifolia (DC.) Nic Lughada \\
& [ined.] \\
& Gomidesia tijucensis (Kiaersk.) \\
Dyrtaceae & Myrcia guianensis (Aubl.) DC. \\
& Myrcia sp.1 \\
& Myrcia splendens (Sw.) DC. \\
\hline Guapira opposita (Vell.) Reitz
\end{tabular}

Continua.. To be continued...

Cerne, Lavras, v. 19, n. 3, p. 489-499, jul./set. 2013 
Tabela 1 - Continuação...

Table 1 - Continued...

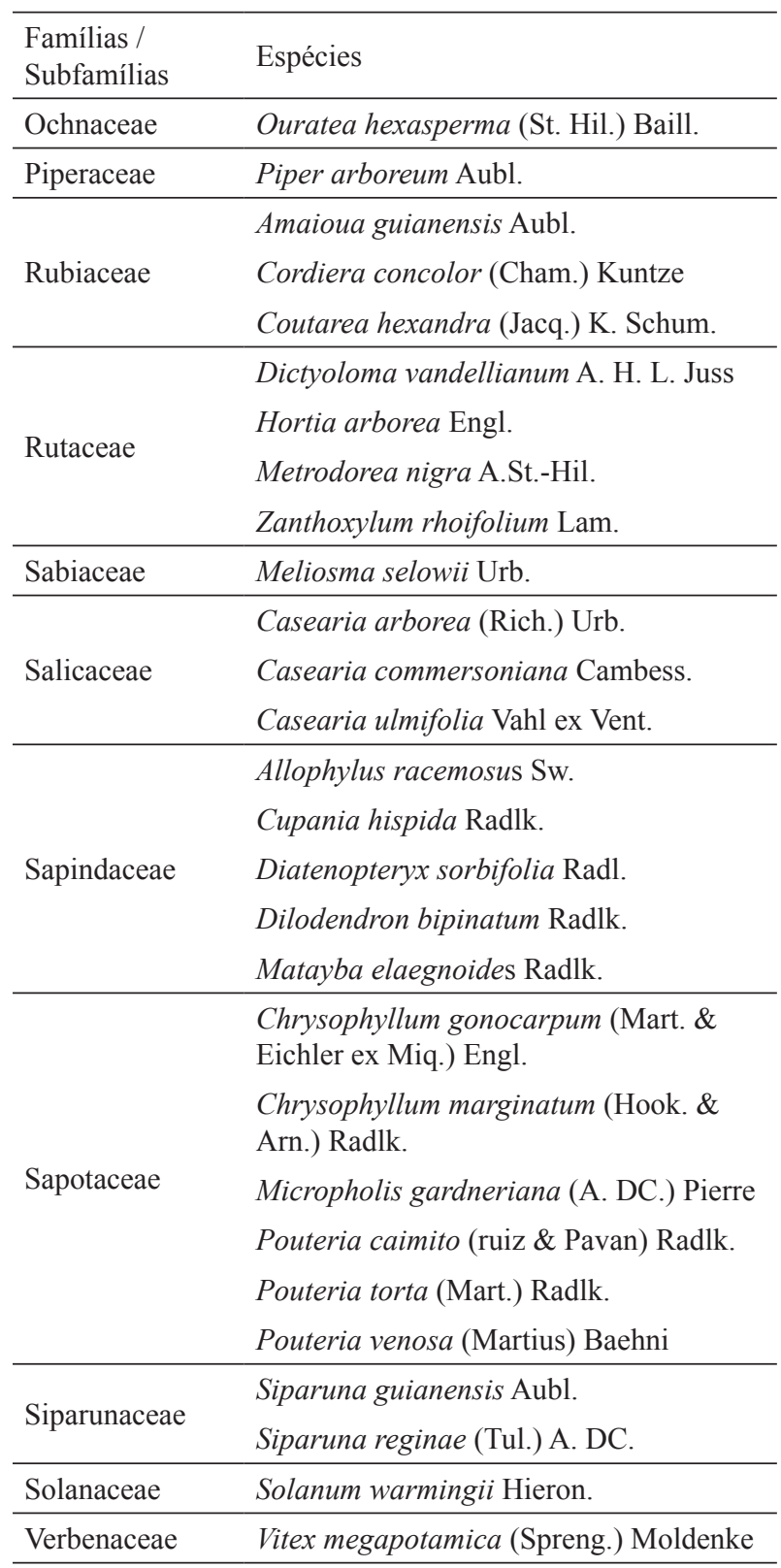

Na faixa Rampa Baixa foram amostradas 93 espécies pertencentes a 72 gêneros e 32 famílias. Acacia polyphylla, Casearia arborea, Lacistema pubescens, Apuleia leiocarpa, Pseudopiptadenia contorta e Siparuna guianensis apresentaram maiores valores de importância (VI) e cobertura (VC) (Tabela 2). O índice de diversidade de Shannon-Wiener ( $\left.\mathrm{H}^{\prime}\right)$ estimado foi de 3,64 e o valor obtido para a equabilidade (J') foi de 0,80 , sendo considerados elevados e compatíveis com os valores obtidos nas Florestas Semideciduais da região, que variam entre 3,2 e 4,02 (LOPES et al., 2002; MEIRA NETO; MARTINS, 2000; SEVILHA et al., 2001) e o valores obtidos para a equabilidade (J'), nas referidas faixas, indicaram uma heterogeneidade florística relativamente alta para o componente arbóreo (LOPES et al., 2002).

A estrutura da Rampa Baixa foi caracterizada principalmente pela espécie Acacia polyphylla, pertencente a família Fabaceae que, por sua vez, é uma família característica de florestas semidecíduas e tem se destacado na maioria dos levantamentos realizados nessa tipologia de comunidades de Mata Atlântica (ARAÚJO et al., 2005; MEIRA NETO; MARTINS, 2000; RIBAS et al., 2003; SILVA et al., 2003). As famílias mais ricas foram Fabaceae com 17 espécies, seguida por Lauraceae (9), Annonaceae (7) e Myrtaceae (7). Dentre as Fabaceae, sete são Mimosoideae, seis Faboideae e quatro Caesalpinioideae. Vale ressaltar que a grande riqueza e abundância de Myrtaceae é um bom indicador da manutenção da diversidade e de várias interações ecológicas, especialmente as que envolvem animais e plantas (CARIM et al., 2007). Segundo Rocha e Silva (2002), essa família possui muitas espécies atrativas de vertebrados dispersores que, por sua vez, são elementos chave para a continuidade do processo sucessional.

Na Baixa Encosta, foram amostradas 89 espécies pertencentes a 32 famílias e 64 gêneros. A estrutura dessa vegetação é caracterizada principalmente pela espécie Casearia arborea, que possui os maiores VI, $\mathrm{VC}$, frequência e densidade. Outras espécies com elevados VI e VC foram Pseudopiptadenia contorta, Matayba elaeagnoides e Lacistema pubescens (Tabela 2), cabendo ressaltar que todas essas espécies apresentaram altos valores de área basal na Baixa Encosta. O índice de diversidade de Shannon-Wiener (H') foi de 3,49 e equabilidade (J') foi de 0,78 . As famílias mais ricas foram Fabaceae com 12 espécies, seguida por Annonaceae (8), Lauraceae (8), Melastomataceae (5) e Myrtaceae (5). Dentre as Fabaceae, seis são Faboideae, quatro Mimosoideae e duas Caesalpinioideae. Fabaceae é a família de maior destaque na área de estudo, em função da importância estrutural de seus representantes Apuleia leiocarpa, Tachigali subvelutina, Abarema brachystachya, Pseudopiptadenia contorta, Stryphnodendron guianense, Dalbergia brasiliensis,

Cerne, Lavras, v. 19, n. 3, p. 489-499, jul./set. 2013 
Tabela 2 - Parâmetros fitossociológicos das espécies amostradas em 1,20 ha de Floresta Estacional Semidecidual Mata do Mumbaça. Faixas Rampa Baixa, Baixa Encosta, Alta Encosta e Topo, município de Dionísio, MG, ordenadas de forma decrescente em valor de importância, em que DA = densidade absoluta (número de indivíduos/ha); DR = densidade relativa (\%); FA = frequência absoluta; $\mathrm{FR}=$ frequência relativa $(\%) ; \mathrm{DoA}=$ dominância absoluta $\left(\mathrm{m}^{2} / \mathrm{ha}\right) ; \mathrm{DoR}=$ dominância relativa $(\%) ; \mathrm{VI} \%=$ valor de importância $(\%)$ e $\mathrm{VC} \%=$ valor de cobertura $(\%)$.

Table 2 - Phytossociological parameters of species sampled in 1.20 ha Semidecidual Seasonal Forest of Forest Mumbaça.Low Ramp, Lower Slope, Upper Slope and Top, the city of Dionísio-MG, ordered in decreasing value of importance, where DA $=$ absolute density (number of individuals/ha), $D R=$ relative density (\%), $F A=$ absolute frequency, $F R=$ relative frequency $(\%), D o A=$ absolute dominance $\left(\mathrm{m}^{2} / \mathrm{ha}\right)$, DoR $=$ relative dominance $(\%)$, VI\% $=$ importance value $(\%)$ and $V C \%=$ cover value $(\%)$.

\begin{tabular}{|c|c|c|c|c|c|c|c|c|}
\hline Espécies & DA & DR & FA & FR & DoA & DoR & VI $(\%)$ & $\mathrm{VC}(\%)$ \\
\hline \multicolumn{9}{|c|}{ Rampa Baixa } \\
\hline Acacia polyphylla & 48 & 6,53 & 67 & 4,48 & 5,75 & 23,36 & 11,46 & 14,95 \\
\hline Casearia arborea & 84 & 11,43 & 90 & 6,05 & 2,05 & 8,33 & 8,6 & 9,88 \\
\hline Lacistema pubescens & 57 & 7,76 & 67 & 4,48 & 0,87 & 3,54 & 5,26 & 5,65 \\
\hline Apuleia leiocarpa & 30 & 4,08 & 57 & 3,81 & 1,74 & 7,09 & 4,99 & 5,59 \\
\hline Newtonia contorta & 16 & 2,18 & 47 & 3,14 & 1,74 & 7,06 & 4,13 & 4,62 \\
\hline Siparuna guianensis & 40 & 5,44 & 60 & 4,04 & 0,41 & 1,68 & 3,72 & 3,56 \\
\hline Myrcia fallax & 17 & 2,31 & 43 & 2,91 & 0,61 & 2,48 & 2,57 & 2,40 \\
\hline Pouteria venosa & 24 & 3,27 & 30 & 2,02 & 0,52 & 2,12 & 2,47 & 2,70 \\
\hline Xylopia sericea & 15 & 2,04 & 30 & 2,02 & 0,79 & 3,22 & 2,43 & 2,63 \\
\hline Hortia arborea & 13 & 1,77 & 33 & 2,24 & 0,78 & 3,19 & 2,42 & 2,62 \\
\hline Demais espécies & 326 & 55,65 & 584 & 39,23 & 18,34 & 74,56 & 56,49 & 65,11 \\
\hline Total & 735 & 100 & 1487 & 100 & 24,6 & 100 & 100 & 100 \\
\hline \multicolumn{9}{|c|}{ Baixa Encosta } \\
\hline Casearia arborea & 176 & 21,5 & 100 & 6,85 & 2,27 & 12,3 & 13,53 & 16,90 \\
\hline Anadenanthera peregrina & 22 & 2,68 & 40 & 2,74 & 2,98 & 16,2 & 7,19 & 9,44 \\
\hline Matayba elaeagnoides & 52 & 6,34 & 70 & 4,79 & 1,24 & 6,69 & 5,94 & 6,52 \\
\hline Lacistema pubescens & 49 & 5,98 & 63 & 4,34 & 0,92 & 5,01 & 5,11 & 5,50 \\
\hline Myrcia fallax & 36 & 4,39 & 57 & 3,88 & 1,21 & 6,57 & 4,95 & 5,48 \\
\hline Tapirira guianensis & 12 & 1,46 & 27 & 1,83 & 1,07 & 5,78 & 3,02 & 3,62 \\
\hline Hortia arborea & 12 & 1,46 & 30 & 2,05 & 0,89 & 4,83 & 2,78 & 3,15 \\
\hline Miconia calvescens & 32 & 3,9 & 37 & 2,51 & 0,29 & 1,57 & 2,66 & 2,74 \\
\hline Xylopia aromatica & 16 & 1,95 & 43 & 2,97 & 0,34 & 1,81 & 2,24 & 1,88 \\
\hline Pouteria torta & 16 & 1,95 & 43 & 2,97 & 0,19 & 1,05 & 1,99 & 1,50 \\
\hline Demais espécies & 321 & 60,88 & 597 & 40,87 & 12,7 & 68,85 & 56,82 & 64,87 \\
\hline Total & 820 & 100 & 1460 & 100 & 18,46 & 100 & 100 & 100 \\
\hline \multicolumn{9}{|c|}{ Alta Encosta } \\
\hline Casearia arborea & 147 & 16,9 & 100 & 5,95 & 1,63 & 9,54 & 10,8 & 13,22 \\
\hline Lacistema pubescens & 114 & 13,1 & 93 & 5,56 & 1,13 & 6,63 & 8,43 & 9,87 \\
\hline Matayba elaeagnoides & 53 & 6,09 & 70 & 4,17 & 1,84 & 10,8 & 7,02 & 8,45 \\
\hline
\end{tabular}

Continua...

To be continued...

Cerne, Lavras, v. 19, n. 3, p. 489-499, jul./set. 2013 
Tabela 2 - Continuação...

Table 2 - Continued...

\begin{tabular}{|c|c|c|c|c|c|c|c|c|}
\hline Espécies & $\mathrm{DA}$ & DR & FA & FR & DoA & DoR & VI (\%) & $\mathrm{VC}(\%)$ \\
\hline \multicolumn{9}{|c|}{ Alta Encosta } \\
\hline Myrcia fallax & 31 & 3,56 & 67 & 3,97 & 0,92 & 5,4 & 4,31 & 4,48 \\
\hline Dalbergia nigra & 18 & 2,07 & 43 & 2,58 & 0,91 & 5,32 & 3,32 & 3,70 \\
\hline Xylopia aromatica & 27 & 3,1 & 43 & 2,58 & 0,44 & 2,58 & 2,75 & 2,84 \\
\hline Aniba firmula & 22 & 2,53 & 53 & 3,17 & 0,26 & 1,52 & 2,41 & 2,03 \\
\hline Anadenanthera peregrina & 8 & 0,92 & 23 & 1,39 & 0,79 & 4,61 & 2,31 & 2,77 \\
\hline Tapirira guianensis & 10 & 1,15 & 27 & 1,59 & 0,72 & 4,2 & 2,31 & 2,68 \\
\hline Himatanthus phagedaenicus & 16 & 1,84 & 50 & 2,98 & 0,22 & 1,3 & 2,04 & 1,57 \\
\hline Demais espécies & 368 & 57,7 & 642 & 38,31 & 9,86 & 57,78 & 51,26 & 57,74 \\
\hline Total & 870 & 100 & 1680 & 100 & 17,06 & 100 & 100 & 100 \\
\hline \multicolumn{9}{|c|}{ Topo } \\
\hline Casearia arborea & 90 & 10,95 & 97 & 5,7 & 1,05 & 5,43 & 7,36 & 8,19 \\
\hline Anadenanthera peregrina & 12 & 1,46 & 27 & 1,57 & 2,38 & 12,31 & 5,11 & 6,89 \\
\hline Machaerium brasiliense & 35 & 4,26 & 63 & 3,73 & 1 & 5,18 & 4,39 & 4,72 \\
\hline Xylopia aromatica & 30 & 3,65 & 60 & 3,54 & 1,06 & 5,46 & 4,22 & 4,56 \\
\hline Astronium fraxinifolium & 38 & 4,62 & 73 & 4,32 & 0,7 & 3,64 & 4,19 & 4,13 \\
\hline Aniba firmula & 35 & 4,26 & 60 & 3,54 & 0,89 & 4,58 & 4,12 & 4,42 \\
\hline Erythroxylum pelleterianum & 37 & 4,5 & 77 & 4,52 & 0,43 & 2,2 & 3,74 & 3,35 \\
\hline Myrcia rufipes & 45 & 5,47 & 60 & 3,54 & 0,36 & 1,87 & 3,63 & 3,67 \\
\hline Matayba elaeagnoides & 22 & 2,68 & 40 & 2,36 & 1 & 5,18 & 3,41 & 3,93 \\
\hline Demais espécies & 431 & 47,57 & 634 & 37,34 & 10,03 & 51,85 & 45,58 & 49,71 \\
\hline Total & 822 & 100 & 1697 & 100 & 19,36 & 100 & 100 & 100 \\
\hline
\end{tabular}

Dalbergia nigra, Lonchocarpus costatus, Machaerium brasiliense, Swartzia apetala e Swartzia polyphylla. Merece destaque a espécie Dalbergia nigra, declarada como oficialmente ameaçada de extinção pela Portaria $\mathrm{n}^{\mathrm{o}}$ - 37-N, de 03/04/92 do Instituto Brasileiro do Meio Ambiente e dos Recursos Renováveis - IBAMA (1992), a qual até o momento, apresenta-se em Minas Gerais, com distribuição restrita à região de Viçosa e ao Parque Estadual do Rio Doce (SOARES JÚNIOR, 2000).

Em outros trabalhos desenvolvidos em Florestas Estacionais Semideciduais na Zona da Mata mineira, a família Fabaceae também foi a que mais se destacou em número de espécies (LOPES et al., 2002; MEIRA NETO; MARTINS, 2000; PAULA et al., 2002; SILVA et al., 2004; SOARES JÚNIOR, 2000). Considerando as baixas condições de fertilidade natural dos solos da região, principalmente das encostas e topos de morros, a capacidade de fixar nitrogênio apresentada por muitas espécies dessa família é uma importante estratégia de vida (SILVA et al., 2004). Nesse sentido, a família Fabaceae, a mais rica neste estudo, pode apresentar papel singular na recuperação de áreas degradadas, visto que agrega características importantes na ativação e regulação dos recursos disponíveis, permitindo o surgimento de espécies mais exigentes em termos nutricionais dos solos (CAMPELLO, 1998).

$\mathrm{Na}$ Alta Encosta, foram amostradas 89 espécies pertencentes a 66 gêneros e 31 famílias. As espécies Casearia arborea e Lacistema pubescens apresentaram os maiores valores de importância, cobertura, área basal, frequência e densidade. Em seguida, as espécies que apresentaram maiores valores de importância (VI\%) e cobertura (VC\%) foram: Matayba elaeagnoides, Myrcia splendens, Dalbergia nigra e Xylopia aromatica (Tabela 2).

Cerne, Lavras, v. 19, n. 3, p. 489-499, jul./set. 2013 
O índice de diversidade de Shannon-Wiener (H') foi de 3,55 e a equabilidade (J') foi de 0,79 . As famílias mais ricas foram Fabaceae com 14 espécies, seguida por Annonaceae e Myrtaceae (7). Dentre as Fabaceae, seis são Faboideae, cinco Mimosoideae e três Caesalpinioideae.

Em trabalhos desenvolvidos na região de ViçosaMG, constatou-se que as famílias com maior número de espécies foram Fabaceae (Caesalpinioideae, Mimosoideae e Faboideae), Myrtaceae, Rubiaceae, Lauraceae e Euphorbiaceae (MARANGON et al., 2003; MEIRA NETO; MARTINS, 2002; PAULA et al., 2002; RIBAS et al., 2003; SILVA et al., 2003). Resultados semelhantes foram encontrados por Leitão-Filho (1982), em Florestas Semideciduais no Estado de São Paulo. Em outras Florestas Estacionais Semideciduais, na região sudoeste de Minas Gerais, Oliveira-Filho et al. (1994) e Oliveira-Filho e Machado (1993) relataram as famílias mais ricas como sendo Leguminosae (Fabaceae), Lauraceae, Myrtaceae, Euphorbiaceae e Annonaceae. Apesar de esse padrão se estender dentro dessa tipologia florestal, existe uma variação na ordem de riqueza entre famílias nas diferentes áreas estudadas, diferindo de acordo com características ambientais e do histórico de uso de cada ambiente.

No Topo, foram amostradas 88 espécies pertencentes a 66 gêneros e 34 famílias. Dentre as espécies amostradas, 26 foram representadas por apenas um indivíduo, correspondendo a, aproximadamente, $30 \%$ do total. O número de indivíduos e sua distribuição pelo ambiente determinaram a posição hierárquica das espécies Lacistema pubescens, Xylopia sericea e Erythroxylum pelleterianum que, por sua vez, apresentaram baixos valores de área basal. Casearia arborea, Pseudopiptadenia contorta, Machaerium brasiliense e Xylopia aromatica (Tabela 2). O Índice de diversidade de Shannon-Wiener (H') apresentou o valor de 3,73 e a equabilidade (J') de 0,83 . Cabe ressaltar que a estrutura dessa vegetação foi caracterizada principalmente pela espécie Casearia arborea por possuir maior VI, VC, frequência e densidade. As famílias mais ricas no Topo foram Fabaceae com 15 espécies, seguida por Annonaceae (6), Myrtaceae e Lauraceae. Dentre as Fabaceae, seis são Faboideae, cinco Caesalpinioideae e quatro Mimosoideae. Em relação à densidade do Topo, valores elevados para esse parâmetro indicam que as espécies Lacistema pubescens, Xylopia sericea e Erythroxylum pelleterianum apresentam-se bem adaptadas à atual sere sucessional, ou seja, são competitivas nas condições ambientais do momento (LOPES et al., 2002).

Cerne, Lavras, v. 19, n. 3, p. 489-499, jul./set. 2013
A riqueza das famílias no Topo corroborou com os resultados de (DRUMOND; MEIRA NETO, 1999) para a composição e estrutura da Zona de Amortecimento do Parque Estadual do Rio Doce, caso seja necessário subsidiar ações de manejo e recuperação de áreas com características similares. A grande heterogeneidade ambiental verificada a curtas distâncias, dentro do mesmo fragmento, confirma que a estrutura atual da floresta nos quatro gradientes estudados não obtiveram monodominância de nenhuma espécie (Tabela 2). Analisando ainda os quatro gradientes topográficos, somente Casearia arborea e Pseudopiptadenia contorta estiveram presentes entre as dez espécies com maiores valores de importância e cobertura no gradiente estudado (Tabela 2).

A similaridade florística entre a Rampa Baixa, Baixa Encosta, Alta Encosta e Topo, verificada por meio do índice de Sørensen, revela semelhança florística entre Alta Encosta e Topo $(0,814)$ e distinção com a Rampa Baixa $(0,653)$. Verifica-se que os mais altos valores de similaridade foram encontrados entre as faixas mais próximas (Alta Encosta e Topo), em contrapartida, menores semelhanças foram obtidas entre as faixas Rampa Baixa e Baixa Encosta (Figura 1).

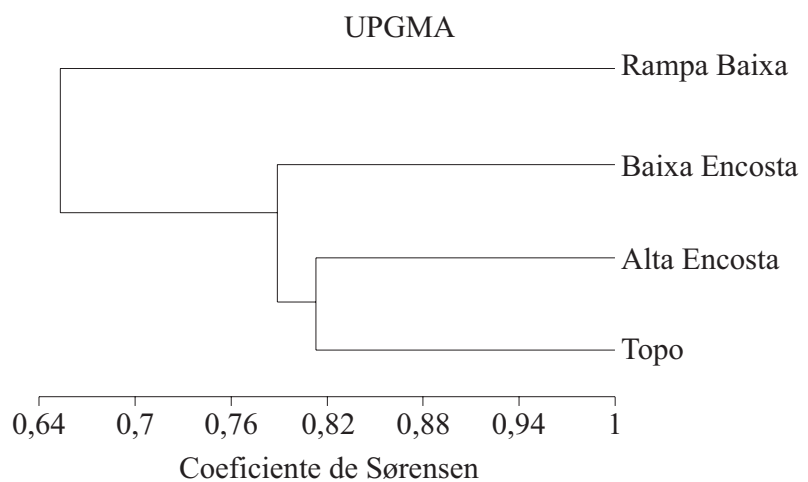

Figura 1 - Dendrograma de similaridade obtido pelo método UPGMA, com base no índice de Sørensen, para as quatro faixas topográficas ao longo do gradiente de uma Floresta Estacional Semidecidual, Mata do Mumbaça, Dionísio-MG.

Figure 1 - Dendrogram of similarity obtained by the UPGMA method, based on Sørensen index for four tracks along the topographic gradient of Semidecidual Seasonal Forest of Forest Mumbaça, Dionísio-MG.

A Rampa Baixa apresentou a menor similaridade florística em relação às demais faixas, evidenciando particularidades, destacando a "preferência" por habitats 
de espécies como Annona cacans, Chrysophyllum marginatum, Cybistax antisyphilitica, Dilodendron bipinatum, Guarea macrophylla, Inga capitata, Inga leptantha, Maytenus communis, Ocotea corymbosa, Parinari brasiliensis, Piper arboreum e Plathypodium elegans que, segundo Souza (2008), esse grupo de espécies mostra-se correlacionado com condições melhores de fertilidade. Resende et al. (1988, 2002) argumentam que nos solos distróficos, quanto maior a declividade, maior será a perda de nutrientes por erosão e lixiviação, sendo a erosão um processo mais pronunciado do que a lixiviação, caracterizando um ambiente mais instável, com ganhos por intemperização muito pequenos, em razão da ausência de minerais primários facilmente decomponíveis.

\section{CONCLUSÕES}

Os resultados mostram que a variação estrutural da Mata do Mumbaça resulta de um gradiente geomorfológico. Áreas planas e com menos erosão local do solo mostram maiores índices de diversidade e maiores números de espécies raras. O componente arbóreo da Floresta Estacional Semidecidual "Mata do Mumbaça" numa Toposequência da Zona de Amortecimento do Parque Estadual do Rio Doce mostrou relação da composição e estrutura dessa floresta com a topografia, sendo fundamental elaboração de um sistema de manejo das florestas de terreno ondulado a fortemente ondulado da Zona de Amortecimento do PERD.

\section{REFERÊNCIAS}

ANGIOSPERM PHYLOGENY GROUP. An update of the Angiosperm Phylogeny Group classification for the orders and families of flowering plants: APG III. Botanical Journal of the Linnean Society, London, v. 161, p. 105-121, 2009.

ARAÚJO, F. S.; MARTINS, S. V.; MEIRA NETO, J. A. A.; LANI, J. L.; PIRES, I. E. Florística da vegetação arbustivoarbórea colonizadora de uma área degradada por mineração de caulim, em Brás Pires, MG. Revista Árvore, Viçosa, v. 29, n. 6, p. 107-136, nov./dez. 2005.

BOTREL, R. T.; OLIVEIRA FILHO, A. T.; RODRIGUES, L. A.; CURI, N. Influência do solo e topografia sobre as variações da composição florística e estrutura da comunidade arbóreo-arbustiva de uma floresta estacional semidecidual em Ingaí, MG. Revista Brasileira de Botânica, São Paulo, v. 25, p. 195-213, 2002.
BROWER, J. E.; ZAR, J. H. Field and laboratory methods for general ecology. Boston: W. C. Brown, 1984.

CAMPELLO, E. F. C. Sucessão vegetal na recuperação de áreas degradadas. In: DIAS, L. E.; MELLO, L. W. V. (Ed.). Recuperação de áreas degradadas. Viçosa, MG: UFV; SOBRADE, 1998. p. 183-196.

CARIM, S.; SCHWARTZ, G.; SILVA, M. F. F. Riqueza de espécies, estrutura e composição florística de uma floresta secundária de 40 anos no leste da Amazônia. Acta Botânica Brasílica, São Paulo, v. 21, n. 2, p. 293-308, 2007.

CARVALHO, D. A.; OLIVEIRA-FILHO, A. T.; BERG, E. V. D.; FONTES, M. A. L.; VILELA, E. A.; MARQUES, J. J. G. S. M.; CARVALHO, W. A. C. Variações florísticas e estruturais do componente arbóreo de uma floresta ombrófila alto-montana às margens do Rio Grande, Bocaina de Minas, MG, Brasil. Acta Botânica Brasílica, São Paulo, v. 19, n. 1, p. 91-109, 2005.

\section{CONSULTORIA E DESENVOLVIMENTO DE SISTEMAS.}

Mata nativa 2: manual do usuário: sistema para análise fitossociológica e elaboração de inventários e planos de manejo de florestas nativas. Viçosa, MG, 2006. 295 p.

DRUMOND, M. A.; MEIRA NETO, J. A. A. Composições florística e fitossociológica de uma mata secundária de um trecho de Mata Atlântica. Ciência Rural, Santa Maria, v. 29, p. 657-661, 1999.

ESPÍRITO-SANTO, F. D. B.; OLIVEIRA-FILHO, A. T.; MACHADO, E. L. M.; SOUZA, J. S.; FONTES, M. A. L.; MARQUES, J. J. G. S. M. Variáveis ambientais e a distribuição de espécies arbóreas em um remanescente de floresta estacional semidecídua montana no campus da Universidade Federal de Lavras, MG. Acta Botânica Brasílica, São Paulo, v. 16, n. 3, p. 331-356, 2002.

FERREIRA JÚNIOR, W. G.; SILVA, A. F.; SCHAEFER, C. E. G. R.; MEIRA NETO, J. A. A.; DIAS, A. S.; IGNÁCIO, M.; MEDEIROS, M. C. M. P. Influence of soils and topographic gradients on tree species distribution in a Brazilian Atlantic Tropical Semideciduous Forest. Edinburgh Journal of Botany, Edinburgh, v. 64, p. 137-157, 2007.

GILHUIS, J. P. Vegetation survey of the Parque Florestal Estadual do Rio Doce, MG, Brasil. 1986. 112 f. Dissertation (Master's Degree in Forest Science) - Agricultural University Wageningen, Wageningen, 1986.

Cerne, Lavras, v. 19, n. 3, p. 489-499, jul./set. 2013 
INSTITUTO BRASILEIRO DO MEIO AMBIENTE E DOS RECURSOS RENOVÁVEIS. Lista oficial das espécies da flora brasileira ameaçadas de extinção. Brasília, 1992.

KOVACH, W. L. A multivariate statistical package for Windows. Version 3.1. Pentraeth: Kovach Computing Services, 1999.

LEITÃO FILHO, H. F. Aspectos taxonômicos das florestas do Estado de São Paulo. Silvicultura em São Paulo, São Paulo, v. 1, p. 197-206, 1982.

LOMBARDI, J. A.; GONÇALVES, M. Composição florística de dois remanescentes de Mata Atlântica do sudeste de Minas Gerais, Brasil. Revista Brasileira de Botânica, São Paulo, v. 23, n. 3, p. 255-282, 2000.

LOPES, W. P.; SILVA, A. F.; SOUZA, A. L.; MEIRA NETO, J. A. A. Estrutura fitossociológica de um trecho de vegetação arbórea no Parque Estadual do Rio Doce - Minas Gerais, Brasil. Acta Botânica Brasílica, São Paulo, v. 16, n. 4, p. 443-456, 2002.

MARANGON, L. C.; SOARES, J. J.; FELICIANO, A. L. Florística arbórea da Mata da Pedreira, município de Viçosa, Minas Gerais. Revista Árvore, Viçosa, v. 27, n. 2, p. 207-216, mar./abr. 2003.

MARTINS, S. V.; SILVA, N. R. S.; SOUZA, A. L.; MEIRA NETO, J. A. Distribuição de espécies arbóreas em um gradiente topográfico de Floresta Estacional Semidecidual em Viçosa, MG. Scientia Forestalis, Piracicaba, v. 64, p. 172-181, 2003.

MEIRA NETO, J. A. A.; MARTINS, F. R. Composição florística de uma floresta estacional semidecidual montana no município de Viçosa, MG. Revista Árvore, Viçosa, v. 26, n. 4, p. 437-446, jul./ago. 2002.

MEIRA NETO, J. A. A.; MARTINS, F. R. Estrutura da Mata da Silvicultura, uma floresta estacional semidecidual montana no município de Viçosa, MG. Revista Árvore, Viçosa, v. 24, n. 2, p. 151-160, mar./abr. 2000.

MOBOT. Missouri Botanical Garden. Disponível em: $<$ http://www.mobot.org/W3T/search/vast.html > . Acesso em: 10 nov. 2012.

MUELLER-DOMBOIS, D. Y.; ELLENBERG, M. Aims and methods in vegetation ecology. New York: J. Wiley, 1974. 547 p.
OLIVEIRA-FILHO, A. T.; MACHADO, J. N. M. Composição florística de uma floresta semidecidua montana na serra de São Jose, Tiradentes, MG. Acta Botânica Brasílica, São Paulo, v. 7, n. 2, p. 71-88, 1993.

OLIVEIRA FILHO, A. T.; SCOLFORO, J. R.; MELLO, J. M. Composição florística e estrutura comunitária de um remanescente de floresta semidecídua montana em Lavras, MG. Revista Brasileira de Botânica, São Paulo, v. 17, n. 2, p. 167-182, 1994.

PAULA, A.; SILVA, A. F.; SOUZA, A. L.; SANTOS, F. A. M. Alterações florísticas ocorridas em um período de quatorze anos na vegetação arbórea de uma Floresta Estacional Semidecidual em Viçosa, MG. Revista Árvore, Viçosa, v. 26, n. 6, p. 743-749, nov./dez. 2002.

PIELOU, E. C. Ecological diversity. New York: J. Wiley, 1975. $165 \mathrm{p}$.

PINTO, S. I. C.; MARTINS, S. V.; SILVA, A. G.; SCOSS, L. M.; TEIXEIRA, H. C. Estrutura do componente arbustivoarbóreo em dois estádios sucessionais de floresta estacional semidecidual na Reserva Florestal Mata do Paraíso, Viçosa, MG, Brasil. Revista Árvore, Viçosa, v. 31, p. 823-833, 2007.

RESENDE, M.; CURI, N.; REZENDE, S. B.; CORRÊA, G. F. Pedologia: base para distinção de ambientes. 4. ed. Viçosa, MG: NEPUT, 2002.

RESENDE, M.; CURI, N.; SANTANA, D. P. Pedologia e fertilidade do solo: interações e interpretações. Brasília: Ministério da Agricultura; Lavras: UFLA/FAEPE, 1988.

RIBAS, R. F.; MEIRA NETO, J. A. A.; SILVA, A. F. da; SOUZA, A. L. de. Composição florística de dois trechos em diferentes etapas serais de uma Floresta Estacional Semidecidual em Viçosa, Minas Gerais. Revista Árvore, Viçosa, v. 27, n. 6, p. 821-830, nov./dez. 2003.

ROCHA, A. E. S.; SILVA, M. F. F. Catálogo de espécies de floresta secundária. Belém: Museu Paraense Emílio Goeldi, 2002.

ROCHA, C. T. V.; CARVALHO, D. A.; FONTES, M. A. L.; OLIVEIRA-FILHO, A. T.; BERG, E. V. D.; MARQUES, J. J. G. S. M. Comunidade arbórea de um continuum entre floresta paludosa e de encosta em Coqueiral, Minas Gerais, Brasil. Revista Brasileira de Botânica, São Paulo, v. 28, n. 2, p. 203-218, 2005.

Cerne, Lavras, v. 19, n. 3, p. 489-499, jul./set. 2013 
RODRIGUES, L. A.; CARVALHO, D. A.; OLIVEIRA FILHO, A. T.; CURI, N. Efeitos de solos e topografia sobre a distribuição de espécies arbóreas em um fragmento de floresta estacional semidecidual, em Luminárias, MG.

Revista Árvore, Viçosa, v. 31, n. 1, p. 25-35, jan./fev. 2007.

SEVILHA, A. C.; PAULA, A.; LOPES, W. P.; SILVA, A. F. Fitossociologia do estrato arbóreo de um trecho de floresta estacional no Jardim Botânico da Universidade Federal de Viçosa (Face Sudoeste), Viçosa, Minas Gerais. Revista Árvore, Viçosa, v. 25, n. 4, p. 431-443, jul./ago. 2001.

SILVA, A. F.; OLIVEIRA, R. V.; SANTOS, N. R. L.; PAULA, A. Composição florística e grupos ecológicos das espécies de um trecho de floresta semidecídua submontana da Fazenda São Geraldo, Viçosa, MG. Revista Árvore, Viçosa, v. 27, n. 3, p. 311-319, maio/jun. 2003.
SILVA, N. R. S.; MARTINS, S. V.; MEIRA NETO, J. A. A.; SOUZA, A. L. Composição florística e estrutura de uma Floresta Estacional Semidecidual Montana em Viçosa, MG.

Revista Árvore, Viçosa, v. 28, n. 3, p. 397-405, maio/jun. 2004.

SOARES JÚNIOR, F. J. Composição florística e estrutura de um fragmento de Floresta Estacional Semidecidual na Fazenda Tico-Tico, Viçosa, MG. 2000. 68 f. Dissertação (Mestrado em Botânica) - Universidade Federal de Viçosa, Viçosa, 2000.

SOUZA, P. B. Diversidade florística e atributos pedológicos ao longo de uma encosta com floresta estacional semidecidual submontana, zona de amortecimento do Parque Estadual do Rio Doce, MG. 2008. 138 f. Tese (Doutorado em Botânica) - Universidade Federal de Viçosa, Viçosa, 2008.

Recebido: 20 de outubro de 2010; aceito: 25 de março de 2013.

Cerne, Lavras, v. 19, n. 3, p. 489-499, jul./set. 2013 
